\title{
Emerging importance of oxidative stress in regulating striated muscle elasticity
}

\author{
Lisa Beckendorf · Wolfgang A. Linke
}

Received: 2 September 2014 / Accepted: 3 October 2014 / Published online: 6 November 2014

(C) The Author(s) 2014. This article is published with open access at Springerlink.com

\begin{abstract}
The contractile function of striated muscle cells is altered by oxidative/nitrosative stress, which can be observed under physiological conditions but also in diseases like heart failure or muscular dystrophy. Oxidative stress causes oxidative modifications of myofilament proteins and can impair myocyte contractility. Recent evidence also suggests an important effect of oxidative stress on muscle elasticity and passive stiffness via modifications of the giant protein titin. In this review we provide a short overview of known oxidative modifications in thin and thick filament proteins and then discuss in more detail those oxidative stress-related modifications altering titin stiffness directly or indirectly. Direct modifications of titin include reversible disulfide bonding within the cardiacspecific N2-Bus domain, which increases titin stiffness, and reversible $S$-glutathionylation of cryptic cysteines in immunoglobulin-like domains, which only takes place after the domains have unfolded and which reduces titin stiffness in cardiac and skeletal muscle. Indirect effects of oxidative stress on titin can occur via reversible modifications of protein kinase signalling pathways (especially the NO-cGMP-PKG axis), which alter the phosphorylation level of certain disordered titin domains and thereby modulate titin stiffness. Oxidative stress also activates proteases such as matrix-metalloproteinase-2 and (indirectly via increasing the intracellular calcium level) calpain-1, both of which cleave titin to irreversibly reduce titin-based stiffness. Although some of these mechanisms require confirmation in the in vivo setting, there is evidence
\end{abstract}

L. Beckendorf · W. A. Linke ( $\square)$

Department of Cardiovascular Physiology, Institute of

Physiology, Ruhr University Bochum, MA 3/56, 44780 Bochum, Germany

e-mail: wolfgang.linke@rub.de that oxidative stress-related modifications of titin are relevant in the context of biomarker design and represent potential targets for therapeutic intervention in some forms of muscle and heart disease.

Keywords Oxidative modification - Myofilaments · Sarcomere proteins - Titin - Passive tension - Diastolic stiffness

\section{Introduction: Oxidative stress as an important modifier of myocyte properties}

Oxidative stress occurs in the cell when reactive oxygen/ nitrogen species (ROS/RNS) are increased or when the antioxidant defence mechanisms are decreased; i.e., when one or both of these factors go out of balance. Under pathological conditions, ROS can react with and thereby damage DNA, lipids and proteins, initiating tissue damage and cell death. However, at physiological concentrations, ROS can be critical regulators of cellular signalling pathways. ROS/RNS are increased, e.g., in myocardial ische$\mathrm{mia} /$ reperfusion (I/R) injury (Canton et al. 2004), in the course of heart failure (Haywood et al. 1996; Sawyer et al. 2002; Canton et al. 2011), and in various muscular dystrophies, such as dysferlinopathy (Terrill et al. 2013), Duchenne muscular dystrophy (DMD), and the $\mathrm{mdx}$ mouse model of DMD (Haycock et al. 1996; Disatnik et al. 1998; Kim et al. 2013; Canton et al. 2014). Among the targets of oxidative modification are various contractile and regulatory proteins of the sarcomeres, the structural and functional units of striated muscle. Oxidative modification of these myofilament proteins can have dramatic functional consequences, including altered calcium sensitivity of force production, contractile impairment and muscle 


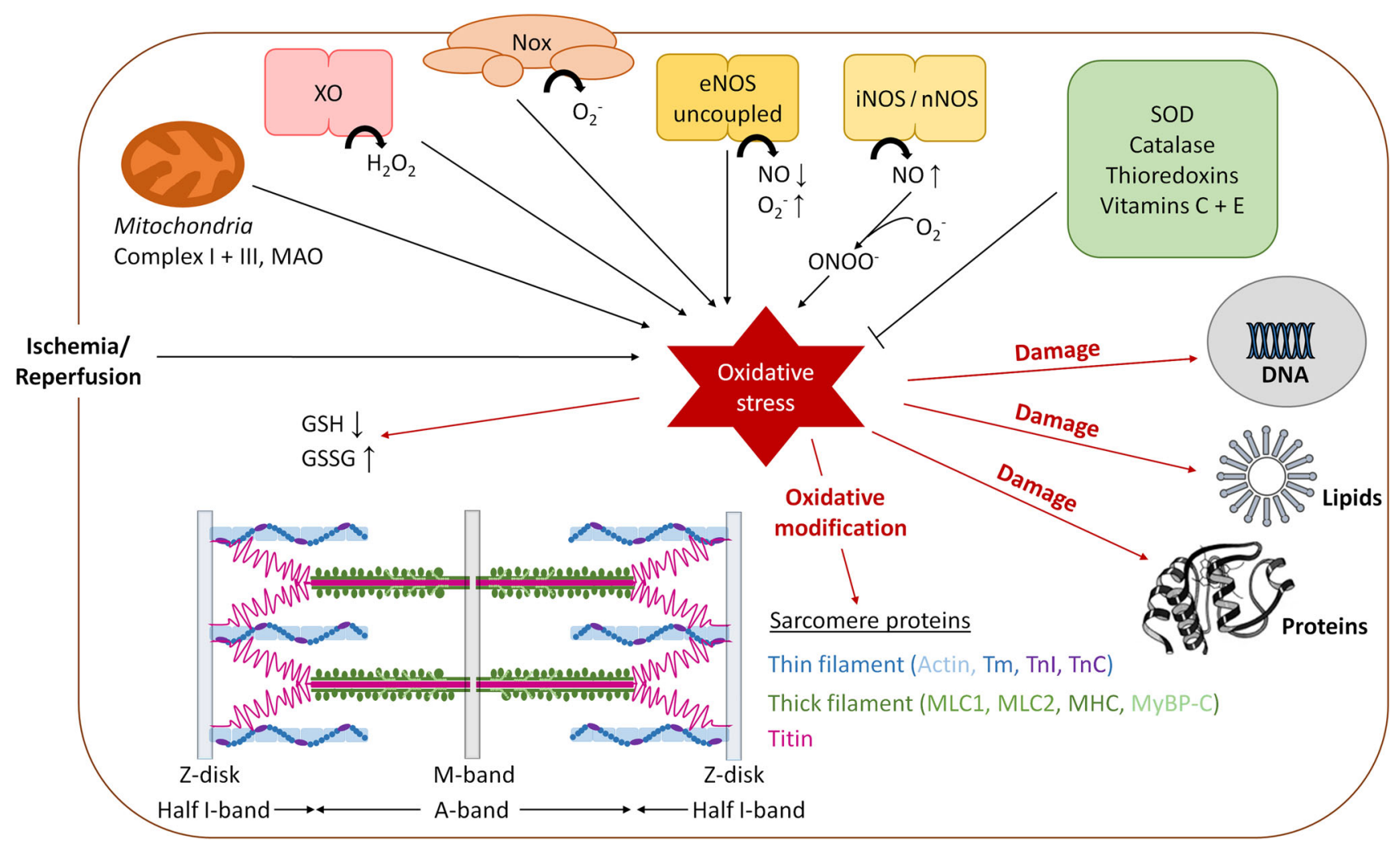

Fig. 1 Schematic overview of important sources and targets of oxidative stress, as well as protectors against it, in striated muscle cells. Sources of reactive oxygen/nitrogen species include xanthine oxidase (XO), NADPH oxidases (Nox), uncoupled endothelial nitric oxide synthase (eNOS), inducible nitric oxide synthase (iNOS), neuronal nitric oxide synthase (nNOS), and mitochondrial factors such as complex I or III and monoamine oxidase (MAO). Antioxidant enzymes include superoxide dismutase (SOD), catalase, and thioredoxins, whereas non-enzymatic antioxidants are vitamins $\mathrm{C}$ and $\mathrm{E}$.

weakness (Andrade et al. 2001; Smith and Reid 2006; Lamb and Westerblad 2011; Balogh et al. 2014), and sometimes also improvements in cardiac or skeletal muscle function (Gao et al. 2012; Lovelock et al. 2012; Mollica et al. 2012).

Important sources of ROS in striated muscle cells (Fig. 1) include xanthine oxidase (XO) (Baldus et al. 2006), NADPH oxidases (Nox) (Heymes et al. 2003), uncoupled endothelial nitric oxide synthase (eNOS) (Xia et al. 1998), inducible nitric oxide synthase (iNOS) (Shah and MacCarthy 2000) as well as neuronal nitric oxide synthase (nNOS) (Zhang et al. 2014), and mitochondrial enzymes such as respiratory chain complex I or III and monoamine oxidase (MAO) (St-Pierre et al. 2002; Di Lisa et al. 2009). Well-known examples of ROS/RNS are hydrogen peroxide $\left(\mathrm{H}_{2} \mathrm{O}_{2}\right)$, hydroxyl radicals $(\mathrm{OH} \cdot)$, superoxide anions $\left(\mathrm{O}_{2}^{-}\right)$, and the highly reactive peroxynitrite $\left(\mathrm{ONOO}^{-}\right)$, which is formed in the reaction of nitric oxide (NO) and $\mathrm{O}_{2}^{-}$(Fig. 1). Antioxidant defense
Oxidative stress damages DNA, lipids, and proteins, and among others, causes oxidation of myofilament proteins and alterations to the ratio between oxidized (GSSG) and reduced forms (GSH) of glutathione. Among the sarcomere proteins biochemically modified by oxidative stress are actin, tropomyosin (Tm), troponin I (TnI) and troponin $\mathrm{C}(\mathrm{TnC})$, myosin light chains 1 and 2 (MLC1 and MLC2), myosin heavy chain (MHC), myosin-binding protein-C (MyBP-C), and titin

mechanisms are also in place, involving enzymes such as catalase and superoxide dismutase (SOD), the thioredoxin system, as well as non-enzymatic factors like vitamins $\mathrm{E}$ and C (Fig. 1). ROS/RNS can alter miscellaneous cellular properties by reacting with amino acids in proteins. These proteins are then modified either reversibly (i.e., the oxidized protein can be enzymatically repaired) or irreversibly (i.e., the oxidized protein must be replaced by de novo synthesis), depending on the nature and amount of ROS (Canton et al. 2014). Reversible modifications caused by ROS/RNS include disulfide bridge formation, $S$-glutathionylation, nitrosylation, and sulfenylation; irreversible modifications include sulfinylation, sulfonylation, nitration, and carbonylation (Canton et al. 2014; Steinberg 2013). Frequent targets of oxidative modification are the thiolcontaining amino acids, cysteine and methionine. Nitration affects predominantly tyrosine residues, whereas the main targets of carbonylation are lysine, arginine, threonine, and proline (Canton et al. 2014). Some of the modifications 
greatly impact protein structure and function, whereas for other modifications, the functional implications are incompletely understood or unknown. The reversibility of oxidative modifications can play a role in signal transduction processes and may also have a protective effect on the protein.

In this review we focus exclusively on the role of oxidative stress in altering the properties and functions of myofilament proteins. We begin with a brief overview of known oxidative modifications in thin and thick filament proteins, before discussing recent evidence for oxidative modifications of the giant titin filament, the protein responsible for the elasticity of cardiac and skeletal myocytes. We also touch on the pathophysiological implications of these findings and the potential for biomarker use and therapeutic intervention in disease. Overall, we make a case for the emerging importance of oxidative modifications of the titin springs in regulating myocyte elasticity and 'passive' stiffness under oxidative stress conditions.

\section{Impact of oxidative stress on thin filament proteins}

Various myofilament proteins are biochemically and functionally altered under oxidative stress. Among these proteins are the components that constitute the sarcomeric thin filaments, actin, tropomyosin, and subunits of troponin (Fig. 1). Mass spectrometry identified actin among the $S$ thiolated cardiomyocyte proteins showing increased abundance in rat hearts following I/R (Eaton et al. 2002). Furthermore, $S$-glutathionylation of actin at $\mathrm{Cys}^{374}$ occurred already at baseline but was substantially elevated under ischemic conditions, and this oxidation impaired the interaction between actin and tropomyosin and the polymerisation of G-actin to F-actin (Dalle-Donne et al. 2003; Chen and Ogut 2006; Passarelli et al. 2010). S-glutathionylation of actin also reduced the activity of the actomyosin S1-ATPase (Pizarro and Ogut 2009). Additionally, carbonylation of actin caused disruption of the actin filaments in vitro (Dalle-Donne et al. 2001). Actin carbonylation was increased in end-stage failing human hearts and correlated with contractile impairment and reduced cardiomyocyte viability (Canton et al. 2011). Moreover, increased carbonylation of actin and other myofilament proteins was shown to be associated with a reduced $\mathrm{Ca}^{2+}$-sensitivity of force production in infarcted mouse hearts (Balogh et al. 2014).

Oxidation of the regulatory protein tropomyosin in microembolized pig hearts decreased contractile function, and this decrease correlated with the formation of tropomyosin homodimers (Canton et al. 2006). Tropomyosin dimer formation due to disulfide bonding was also detected in mouse cardiac tissue following myocardial infarction
(Avner et al. 2012), in isolated rat hearts after postischemic reperfusion (Canton et al. 2004), and in failing rabbit hearts exposed to elevated oxidative stress caused by rapid left ventricular pacing (Heusch et al. 2010). Additionally, tropomyosin formed disulfide bridges with actin in $\mathrm{H}_{2} \mathrm{O}_{2}$ perfused rat hearts (Canton et al. 2004). Nitroxyl (HNO), a RNS activating signalling pathways different from NO (Miranda 2005), caused the formation of actin-tropomyosin heterodimers via actin $\mathrm{Cys}^{257}$ and tropomyosin Cys ${ }^{190}$ (Gao et al. 2012), which probably added to the beneficial effects on myocardial contractile function observed with HNO (Gao et al. 2012; Sabbah et al. 2013; Arcaro et al. 2014). In skeletal myocytes from the mdx mouse model of DMD, ROS production as well as the overall content of oxidized thiols were increased in comparison to wildtype animals, and tropomyosin cross-linking occurred (Menazza et al. 2010; El-Shafey et al. 2011). Nitration of tropomyosin was shown to occur in aging rat skeletal muscles (Kanski et al. 2005b).

The cardiac troponin subunits, cTnI and cTnC, contain tyrosine residues which are targets of nitration in aging rat hearts (Kanski et al. 2005a), although the functional impact from this biochemical modification is not known. The TnI isoform from fast-twitch skeletal muscle was identified as a target of $S$-glutathionylation in rat and human, and this modification increased the $\mathrm{Ca}^{2+}$ sensitivity of the contractile apparatus (Mollica et al. 2012). In this TnI isoform, $\mathrm{Cys}^{133}$ was the only accessible cysteine. Since the phosphorylation of a homologous serine in cTnI impedes the interaction with cTnC (Ward et al. 2001), oxidation of $\mathrm{Cys}^{133}$ in fast-twitch muscle TnI may also lead to a reduced binding affinity to TnC (Mollica et al. 2012).

Taken together, an established effect of oxidative modifications in thin filament proteins is the reduced myofilament $\mathrm{Ca}^{2+}$-sensitivity of force production (although this parameter can transiently increase under oxidative stress), which depresses contractile performance in both cardiac and skeletal muscle (Lamb and Westerblad 2011; Steinberg 2013). Oxidative stress-related effects on the structure of thin filament components and on the actinmyosin interface presumably contribute to the contractile impairment. In some cases, the contractile activity can be improved under oxidizing conditions (Steinberg 2013).

\section{Impact of oxidative stress on thick filament proteins}

Thick filament proteins impaired by oxidative modifications include the myosin light chains 1 and 2 (MLC1 and MLC2), myosin heavy chain (MHC), and cardiac myosinbinding protein-C (cMyBP-C). As regards MLC1 and MLC2, tyrosine nitration $\left(\mathrm{Tyr}^{73}\right.$ and $\mathrm{Tyr}^{185}$ in MLC1, and $\mathrm{Tyr}^{182}$ in MLC2) promoted the degradation of these 
proteins by matrix metalloproteinase-2 (MMP-2) (Doroszko et al. 2010; Polewicz et al. 2011). Nitrotyrosinecontaining sequences from MLC were also detected in aging skeletal muscle (Kanski et al. 2005b). Oxidation of sulfhydryl groups in cysteines or methionines of MLC1 reduced the contractile force of human cardiomyocytes (Hertelendi et al. 2008).

MyBP-C appears to be modified by oxidative stress in various ways (Brennan et al. 2006). The protein showed similar levels of carbonylation in normal and infarcted mouse hearts (Balogh et al. 2014). Reversible $S$-glutathionylation of MyBP-C could be induced in detergentextracted cardiac fibres in vitro by treatment with oxidized glutathione (GSSG) or reducing agent, dithiothreitol (DTT), and the sites of $S$-glutathionylation in MyBP-C were identified as $\mathrm{Cys}^{479}$, $\mathrm{Cys}^{627}$, and Cys ${ }^{655}$ (Patel et al. 2013). These oxidative modifications resulted in enhanced myofilament $\mathrm{Ca}^{2+}$ sensitivity and diastolic dysfunction (Lovelock et al. 2012; Patel et al. 2013).

MHC was found to be nitrated at several different tyrosine residues $\left(\mathrm{Tyr}^{114}, \mathrm{Tyr}^{116}, \mathrm{Tyr}^{134}\right.$, and $\mathrm{Tyr}^{142}$ ) in aging rat heart (Hong et al. 2007) and increased MHC nitration negatively influenced the force generation of rat ventricular trabeculae (Mihm et al. 2003). Peroxynitriteinduced oxidation of two cysteines in MHC (Cys ${ }^{697}$ and $\mathrm{Cys}^{707}$ ) close to the catalytic centre inhibited the activity of the skeletal muscle S1-ATPase and reduced the maximum force (Tiago et al. 2006). Furthermore, in infarcted mouse hearts, the levels of MHC carbonylation were increased, which was suggested to partly explain the contractile impairment of these hearts (Balogh et al. 2014). Treatment of cardiomyocytes with HNO induced cross-bridge formation between cysteines of MHC and MLC1, and this modification was associated with an improved contractility (Gao et al. 2012). In conclusion, an increasing number of oxidative modifications are known to affect the major thick filament proteins, frequently with negative (but sometimes with positive) consequences for cardiomyocyte contractility. Oxidative modification can also predispose some thick filament proteins to increased degradation.

\section{Regulation of muscle elasticity via modifications of titin}

For the remainder of the review, we focus on the titin protein chain, the 'third' filament of the sarcomere next to the thin and thick filaments, and we begin with a brief discussion of some relevant titin properties (for a more comprehensive recent review, see Linke and Hamdani 2014). A well-established function of titin is to help determine the elastic properties of cardiac and skeletal muscles and to generate a 'passive' force upon stretching. The elasticity of titin resides within the extensible I-band portion of the protein, which is differentially spliced, giving rise to the major titin isoforms termed N2BA and N2B (both expressed in cardiac muscle) and N2A (expressed in skeletal muscle). I-band titin is composed of 'proximal', 'middle', and 'distal' (relative to the Z-disk) immunoglobulin-like (Ig-)domain regions; the PEVK domain rich in proline, glutamate, valine, and lysine, which is a disordered region; the N2-A element; and the cardiac-specific N2-B element, which contains a large disordered segment, the N2B-unique sequence (N2-Bus) (Fig. 2). The Igdomain regions and the disordered segments are all involved in the molecular mechanism of titin elasticity (Linke 2000; Linke and Fernandez 2002; Li et al. 2002).

Titin stiffness is regulated in various different ways. In the long-term, the titin isoform size and variant can be altered ('isoform switch'), which greatly affects myocyte passive stiffness. In the perinatal heart, a transition occurs from a highly compliant, fetal N2BA isoform (3.7 MDa) to shorter/less compliant N2BA isoforms and the short/stiff N2B titin (Lahmers et al. 2004; Opitz et al. 2004; Warren et al. 2004). This isoform transition can partially be reversed in the failing human heart, where the N2BA:N2B expression ratio increases again (Neagoe et al. 2002; Makarenko et al. 2004). In the short-term, titin stiffness is regulated by post-translational modifications (Linke and Hamdani 2014). Phosphorylation of the N2-Bus or the PEVK domain is mediated, e.g., by protein kinase (PK)A, cyclic guanosine monophosphate (cGMP) activated $\mathrm{PKG}$, $\mathrm{PKC} \alpha$, or calcium/calmodulin-dependent protein kinase II (CaMKII), and these modifications-with the exception of the PKC $\alpha$-mediated phosphorylation-decrease titin-based stiffness (Yamasaki et al. 2002; Krüger and Linke 2006; Krüger et al. 2009; Hidalgo et al. 2009; Hamdani et al. 2013c). In human heart failure, a phosphorylation deficit was observed, especially for PKG-mediated titin phosphorylation, and this was correlated with increased myocardial stiffness (Krüger et al. 2009; Kötter et al. 2013). Additional means by which titin stiffness can be modulated are now emerging, and these mechanisms are triggered by oxidative stress. The main purpose of this review is to discuss how ROS/RNS can modify the titin springs via different pathways, which can have opposing effects on the protein's stiffness.

\section{Hypo-phosphorylation of titin due to impaired NO/ cGMP/PKG signalling}

NO produced by NOS enzymes (Fig. 1) activates soluble guanylyl cyclase (sGC) by binding to its heme moiety. The sGC then increases cGMP production and thereby activates PKG. This signalling mechanism is impaired by oxidative stress. Under oxidant conditions, eNOS becomes 


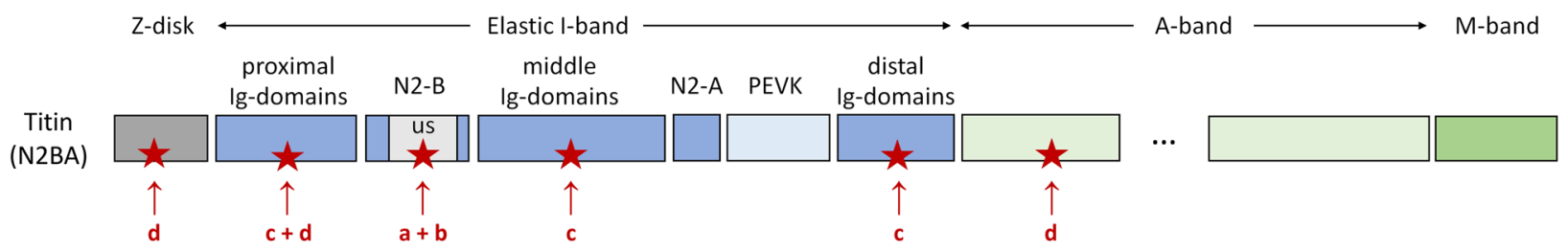

a Hypo-phosphorylation (reversible, indirect)
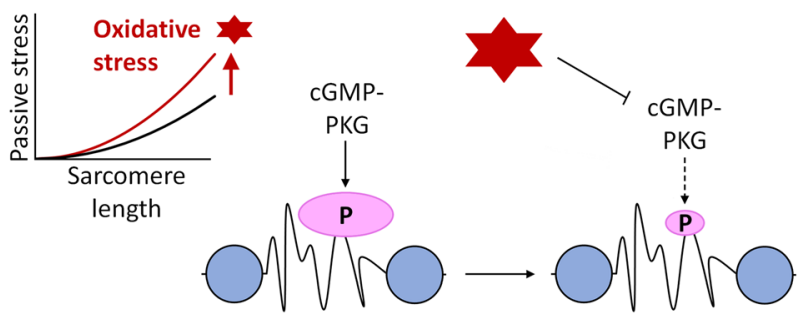

Ig-domain N2-Bus

N2-Bus

\section{S-glutathionylation (reversible, direct)}
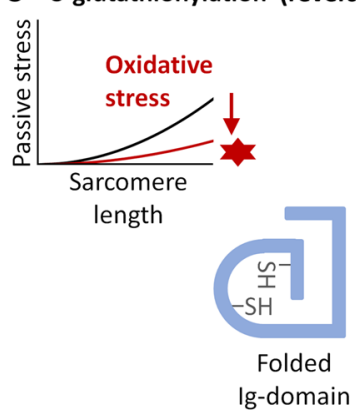

Exposure of cryptic cysteines
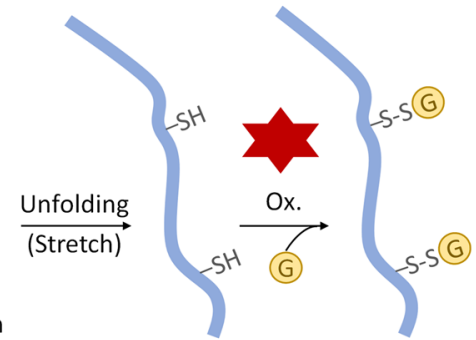

Fig. 2 Oxidative stress-related modifications of titin affecting titinbased passive stiffness. The top panel illustrates the different segments of the titin chain (N2BA isoform) in a half-sarcomere, focusing on the various regions making up the elastic I-band segment. Segments where oxidative modifications occur are marked by arrows; the letters correspond to the respective type of oxidative modification indicated in panels (a-d). a Oxidative stress induces hypo-phosphorylation of the titin N2-Bus as it impairs NO-cGMP-PKG signalling; this modification increases titin stiffness. b Oxidizing conditions

uncoupled by direct $S$-glutathionylation or via depletion of the enzyme's co-factor, tetrahydrobiopterin, which decreases NO but increases the production of the highly reactive superoxide anion, $\mathrm{O}_{2}{ }^{-}$(De Pascali et al. 2014). The lowered NO bioavailability reduces sGC activation and depresses the cGMP-PKG pathway. Moreover, the ferrous heme iron $\mathrm{Fe}^{2+}$ can be oxidized to $\mathrm{Fe}^{3+}$ under oxidative stress, further reducing the activity of sGC (Schrammel et al. 1996).

Due to the impaired NO/cGMP/PKG signalling under oxidizing conditions, titin may become hypo-phosphorylated mainly at the N2-Bus, which would increase the stiffness of the titin spring (Fig. 2a). Evidence that these alterations are presumably important in heart disease comes from the following observations: (i) a PKGdependent titin phosphorylation deficit exists in failing b Disulfide bonding (reversible, direct)

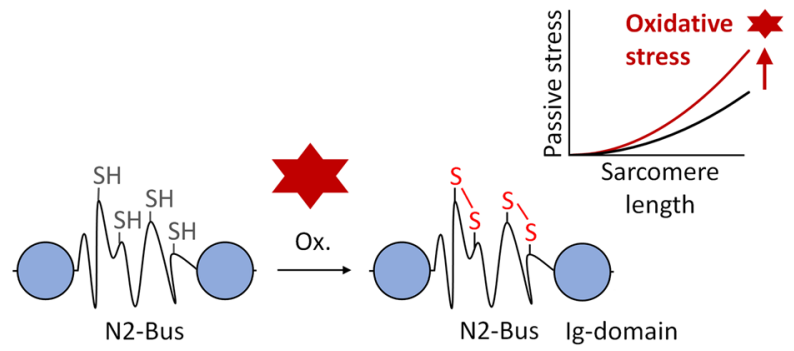

d Cleavage by proteases (irreversible, indirect)

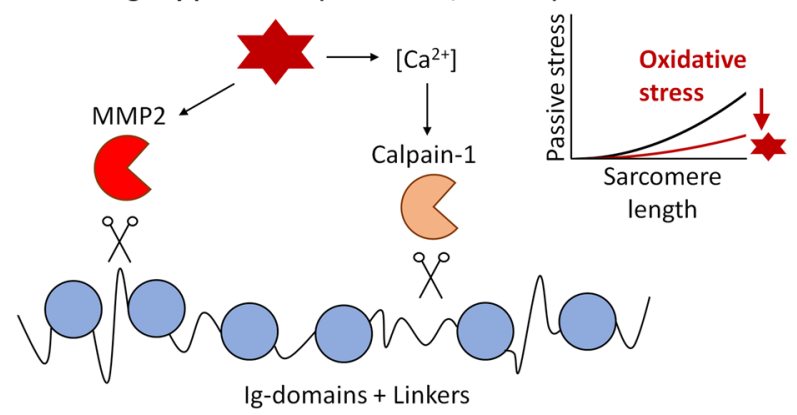

promote the formation of disulfide bonds in the titin N2-Bus; this modification increases titin stiffness. c Under oxidative conditions, buried cysteines in titin immunoglobulin (Ig-)domains are $S$-glutathionylated after they become exposed by domain unfolding (triggered by sarcomere stretch); this modification prevents domain refolding and thus reduces titin stiffness. d Oxidative stress increases the activity of proteases such as matrix metalloproteinase-2 (MMP2) and (via a rise in intracellular $\mathrm{Ca}^{2+}$ concentration) calpain-1, which degrade titin; these alterations would decrease titin stiffness

human hearts, along with increased passive stiffness (Krüger et al. 2009; Kötter et al. 2013); (ii) a reduced myocardial cGMP concentration and PKG activity can be found in human and canine diastolic heart failure (van Heerebeek et al. 2012; Hamdani et al. 2013a); and (iii) increased nitrotyrosine levels are detectable in the hearts of diastolic heart failure patients (van Heerebeek et al. 2012). Furthermore, the pathologically high passive stiffness can be corrected ex vivo by administering cGMP-PKG to isolated cardiomyocytes (Borbély et al. 2009; van Heerebeek et al. 2012; Hamdani et al. 2013a; Hamdani et al. 2013b) and in vivo by boosting the cGMPPKG pathway through pharmacological interventions in the dogs with diastolic heart failure (Bishu et al. 2011). These findings suggest that oxidative/nitrosative stress increases cardiac titin stiffness by impairing upstream 
signalling pathways relevant for PKG-mediated titin phosphorylation.

\section{Disulfide bridge formation in the cardiac titin N2-Bus}

A direct oxidative stress-related modification of titin, which increases cardiomyocyte stiffness, is disulfide bonding in the cardiac-specific N2-Bus (Fig. 2b). Under oxidizing conditions, the six conserved cysteines present in the human N2-Bus can form up to three $\mathrm{S}-\mathrm{S}$ bridges (Grützner et al. 2009). The disordered N2-Bus is thus mechanically stabilized and its extensibility is greatly impaired, as shown by single-molecule force-extension experiments on recombinant $\mathrm{N} 2-\mathrm{B}$ constructs using the atomic force microscope (AFM) (Grützner et al. 2009). Consistent with this, the reducing agent, thioredoxin, had a de-stiffening effect on isolated human cardiomyofibrils exposed to a cyclic stretch-release protocol (Grützner et al. 2009). Moreover, the maximum extension of the N2-Bus studied ex vivo by immunoelectron microscopy of stretched rabbit cardiac sarcomeres was only $\sim 100 \mathrm{~nm}$ if a reducing agent was excluded from the medium (Linke et al. 1999), but $\sim 200 \mathrm{~nm}$ if DTT $(1 \mathrm{mM})$ was present (Trombitás et al. 1999). These values are very close to those measured for the N2-Bus in vitro using AFM force spectroscopy in the absence and presence of DTT, respectively (Grützner et al. 2009). Another aspect is that disulfide bonding in the N2-Bus most certainly also interferes with the regulation of titin stiffness by phosphorylation of this region. Indeed, it was observed that the de-stiffening effect of PKA on isolated cardiac myofibrils, which is caused by phosphorylation of the N2-Bus, is more pronounced in the presence of DTT than in the absence of it (Krüger and Linke 2006).

S-S bridge formation in titin's N2-Bus may not only have a mechanical effect on the cardiomyocyte, but could also modify intracellular signalling pathways intersecting with the N2-Bus (Krüger and Linke 2011). This cardiac titin region binds the four-and-a-half LIM-domain proteins, FHL1 and FHL2 (Lange et al. 2002; Sheikh et al. 2008), and the small heat shock proteins (sHSPs), $\alpha \mathrm{B}$-crystallin and HSP27 (Bullard et al. 2004; Kötter et al. 2014). Disulfide bonds in the N2-Bus could alter these interactions and thus affect pathways of mechanosensation and protein quality control in the cardiomyocyte (Linke and Hamdani 2014). In conclusion, the N2-Bus of cardiac titin is a preferred target of oxidative modification in vitro and probably also in isolated cardiomyocytes. It remains to be established whether $\mathrm{S}-\mathrm{S}$ bonding in the N2-Bus occurs under oxidative stress in vivo and if so, what impact this modification may have on myocardial stiffness and mechanical signalling.

\section{$S$-glutathionylation of cryptic cysteines in the Ig- domains of I-band titin}

A recently elucidated direct modification of titin under oxidative stress is the $S$-glutathionylation of cryptic cysteines in the Ig-domains of the elastic I-band region (Alegre-Cebollada et al. 2014) (Fig. 2c). These cysteines are usually buried inside the Ig-domain fold but become exposed if the Ig-domain unfolds. Out of the maximally 93 Ig-domains present in the I-band titin spring, 89 domains contain cryptic cysteines that can potentially be oxidized upon domain unfolding. Interestingly, the I-band Igdomains of titin contain, on average, between two and three cysteines, whereas most Ig-domains in all other parts of the titin molecule contain only one cysteine (Alegre-Cebollada et al. 2014). The majority of cysteines in the I-band Igdomains are evolutionary well conserved. Some of these cysteines were suggested earlier to form disulfide bridges under oxidizing conditions, with the proximal and middle Ig-domains being a potential hotspot for such modifications (Mayans et al. 2001). However, single-molecule mechanical measurements by AFM force-clamp, using Ig-domain I91 (nomenclature of Bang et al. 2001), revealed that the two buried cysteines contained within this domain usually form mixed disulfides with glutathione in the presence of GSSG-but only if the domain is unfolded (Alegre-Cebollada et al. 2014) (Fig. 2c). The S-glutathionylation decreased the mechanical stability of the domain and prevented domain refolding. Importantly, to inhibit domain refolding, GSSG needed to be exposed for several tens of seconds, whereas exposure for only a few seconds had no or little effect. Treatment with reduced glutathione (GSH) or removal of the two cysteines by site-directed mutagenesis restored the ability of the Ig-domain to refold in the AFM experiments. Furthermore, $S$-glutathionylation of the unfolded I91 domain in the presence of GSSG was confirmed by Western blotting and was found to be fully reversible with the administration of DTT (Alegre-Cebollada et al. 2014). These findings showed for the first time that mechanical unfolding can enable oxidative modification of titin's cryptic cysteines, which disrupt the domain folding/unfolding dynamics and cause sustained but reversible changes in titin elasticity.

Mechanical experiments on single skinned human cardiomyocytes demonstrated that oxidation by GSSG greatly reduces titin-based passive tension if the myocytes are exposed to the oxidizing agent in an over-stretched state favouring Ig-domain unfolding (Alegre-Cebollada et al. 2014). The reduction in cardiomyocyte stiffness is expected, because the unfolding of an Ig-domain causes a gain in contour length by $\sim 30 \mathrm{~nm}$ compared to the folded state, such that the titin spring becomes longer and more extensible (Linke and Fernandez 2002). In the absence of 
over-stretch, GSSG still reduced cardiomyocyte stiffness by some amount (Alegre-Cebollada et al. 2014), due probably to a number of unfolded Ig-domains present in I-band titin at physiological sarcomere lengths (Linke and Fernandez 2002). The reduction in cardiomyocyte stiffness on GSSG-treatment was reversible with GSH or DTT.

In summary, evidence from in vitro and ex vivo experiments suggests that $S$-glutathionylation of cysteines in unfolded titin Ig-domains could be an important mechanism of myocyte stiffness regulation under oxidant stress, in both the heart and the skeletal muscles. In support of this notion, increased $S$-glutathionylation of sarcomere proteins was found in mouse heart tissue following myocardial infarction, and among these proteins was titin (Avner et al. 2012; Alegre-Cebollada et al. 2014). Future studies should explore how important this oxidative modification of titin is in the context of heart failure or muscle disease and to what degree it affects titin-based passive stiffness in vivo.

\section{Titin degradation by oxidative/nitrosative stress- activated proteases}

Yet another way by which oxidative/nitrosative stress could alter titin stiffness is indirectly via activation of proteases that degrade titin (Fig. 2d). One of these proteases is MMP2, which is abundant in the cardiomyocyte (Kandasamy et al. 2010) and localizes to various subcellular compartments, including the Z-disk (Ali et al. 2010). MMP2 cleaved cardiac titin in a concentration-dependent manner and in rat hearts the titin cleavage was increased after myocardial $\mathrm{I} / \mathrm{R}$ injury causing rapid induction of the highly pro-oxidant $\mathrm{ONOO}^{-}$(Ali et al. 2010). Conversely, titin degradation induced by $\mathrm{I} / \mathrm{R}$ damage was diminished by an MMP inhibitor. Previously, oxidative stress-activated MMP2 was shown to degrade various sarcomeric targets next to titin, including TnI, MLC1, and $\alpha$-actinin (Wang et al. 2002; Sawicki et al. 2005; Sung et al. 2007). The MMP2-mediated structural alterations of sarcomeric proteins may be one reason for the reduced myocardial systolic and diastolic dysfunction observed with $\mathrm{I} / \mathrm{R}$ injury (Linke 2010).

The $\mathrm{Ca}^{2+}$-dependent intracellular protease, calpain-1, also degrades titin in cardiomyocytes, preferentially within the elastic spring segment, and calpain inhibitors prevent this degradation (Lim et al. 2004; Barta et al. 2005). Although there is no evidence for direct activation of calpain- 1 by oxidant stress, the protease is thought to be induced by cardiac I/R damage due to $\mathrm{Ca}^{2+}$ overload (Inserte et al. 2012). This increase in calcium levels through oxidative stress occurs by various means, especially via activation/sensitization of the ryanodine receptor $\mathrm{Ca}^{2+}$ release channels (Allen et al. 2008). Interestingly, in the presence of $\mathrm{Ca}^{2+}$, calpain-1 binds to titin's Ig-domain I4 in the proximal I-band region (titin domain nomenclature of Bang et al. 2001) where it could be "stored until further use" in the myocyte (Coulis et al. 2008). A remarkable observation in this context is that titin is more susceptible to calpain-1-mediated proteolysis when it is stretched (Murphy et al. 2006), suggesting that in extended, or perhaps overstretched, sarcomeres titin is particularly susceptible to such proteolysis. Taken together, current evidence suggests that preferential proteolysis of I-band titin by activation of calpain- 1 is an early process in myocyte injury and that oxidative stress may play a role in this structural damage.

Proteolytic degradation of the titin spring segment induced by oxidative stress will decrease the passive stiffness of the myocytes irreversibly (Fig. 2d). Active contraction will also be compromised, as the damage to I-band titin impairs the accurate positioning of the thick filaments in the middle of the sarcomere and thus, force generation by actomyosin (Horowits et al. 1986). Moreover, titin is important for the length-dependent activation of cardiac and skeletal myocytes (Fukuda and Granzier 2005; Mateja et al. 2013) and titin proteolytic damage will depress this function. Increased oxidative stress and severe titin degradation can be observed in human ischemic cardiomyopathy (Hein et al. 1994; Morano et al. 1994), suggesting that a connection exists between these two events, although a causative relationship remains to be proven.

\section{Considerations on the possible net effect of oxidative titin modifications on cell stiffness}

The various direct and indirect effects of oxidative stress on titin (Fig. 2) may occur concomitantly with one another, which would make it unpredictable in which direction they alter the stiffness of the myocyte. Whereas the titin phosphorylation deficit and the disulfide bonding in the N2-Bus will increase titin-based stiffness, the $S$-glutathionylation of cryptic cysteines and the irreversible protease-dependent titin cleavage will decrease it. Which one of these effects may be dominating under which physiological or disease condition in the heart or the skeletal muscles remains to be seen. Notably, the oxidative modifications directed at the titin N2-Bus (Fig. 2a, b) can occur in cardiac but not in skeletal myocytes, because only the former express the N2Bus-containing titin isoforms (N2BA, N2B). In contrast, the protease-mediated titin degradation and the $S$-glutathionylation of cryptic cysteines in titin Ig-domains can take place in both cardiac and skeletal muscle. This $S$-glutathionylation presumably requires increased muscle stretch (increased cardiac preload) in order to exert a significant effect on (cardio) myocyte stiffness. Thus, the higher the 
preload on the cardiac chamber filled under oxidative stress, the more pronounced may be the mechanical weakening due to oxidized, unfolded titin Ig-domains. Along the same line, pre-stretch of a skeletal muscle to long sarcomere length under oxidant conditions may have a noticeable softening effect on that muscle. One can also speculate that oxidative stress in conjunction with high stretch could have a de-stiffening effect on skeletal myocytes but not on cardiomyocytes, because in the latter the different means of oxidative titin modifications may neutralize one another in their effect on total passive stiffness.

Oxidative stress is often coupled with other important changes to the intracellular milieu, especially acidosis (e.g., during I/R). Both these conditions evoke a protective response by the myocyte mediated by inducible heat shock proteins, such as the sHSPs, $\alpha$ B-crystallin and HSP27 (Mymrikov et al. 2011; Larkins et al. 2012). Under oxidant/ acidic stress, these chaperones associate preferentially with the I-band titin springs in both cardiac and skeletal myocytes (Bullard et al. 2004; Kötter et al. 2014). Importantly, the titin-sHSP interaction affects titin stiffness. Folded titin Ig-domains appear to be stabilized mechanically by this interaction (Bullard et al. 2004), whereas unfolded Igdomains are protected from aggregation by sHSP-binding, which prevents excessive myocyte stiffening (Kötter et al. 2014). Whether this binding of sHSPs would interfere with the exposure of cryptic cysteines and their $S$-glutathionylation under oxidizing conditions is unknown. However, the sHSP-titin binding adds to the complexity of possible effects of oxidative stress on titin-based stiffness.

Last but not least, oxidative modifications have been shown to increase the activity of several protein kinases, including PKA, PKG, PKC, and CaMKII (reviewed by Steinberg 2013), and to reduce the activity of protein phosphatases (Wright et al. 2009). Since the phosphorylation state of I-band titin affects titin-based stiffness (Linke and Hamdani 2014), any oxidative stress-mediated increase in kinase activity or reduction in phosphatase activity will also have an impact on myocyte stiffness. In conclusion, while oxidative stress seems almost certain to alter titin stiffness via multiple mechanisms in vivo, the magnitude and the direction of the stiffness modulation need to be established in additional studies.

\section{Oxidative titin modification as a potential biomarker and therapeutic target}

Since oxidative stress plays a crucial role in the pathology of various cardiac and skeletal muscle diseases (see Introduction), the question arises whether oxidative modifications in titin may be characteristic of some of those conditions. Interestingly, in Chagas' disease, which is caused by Trypanosoma cruzi infection but presents with severe cardiac symptoms (cardiomegaly, ventricular dilatation), the increased oxidative/nitrosative stress associated with this disease was shown to cause nitration of Ig-repeats from the cardiac N2B-titin isoform, and the nitrated peptides were detectable in the plasma from a rat model and from patients (Dihman et al. 2008). The nitrated titin was also recognized by antibodies from the host's immune system and evoked a self-directed immune response (Dihman et al. 2012). Thus, ROS/RNS-dependent modifications of titin could indeed serve as biomarkers of specific forms of cardiac and skeletal muscle disease. In this context, titin has recently been suggested as a specific biomarker of DMD detectable in urine samples of affected patients and in serum samples from the $\mathrm{mdx}$ mouse (Rouillon et al. 2014; Hathout et al. 2014). Since oxidative stress is an established hallmark of this muscle disease, it may be worth extending the analysis to oxidated/nitrated titin peptide species to improve marker specificity.

Oxidative titin modifications could also serve as potential therapeutic targets in skeletal or heart muscle diseases associated with myocyte stiffening. While cardiomyocyte stiffening is well-documented especially in diastolic heart failure (Linke and Hamdani, 2014), skeletal muscle fibres can also get stiffer under disease conditions, e.g., in certain neurological disorders (Olsson et al. 2006; Mathewson et al. 2014). An interesting treatment option in heart failure associated with elevated diastolic stiffness may arise from the fact that oxidative stress modulates the NO-cGMP-PKG pathway, an important modifier of titinbased stiffness. In the transition to heart failure, oxidative stress can be triggered by co-morbidities, such as old age, renal insufficiency, obesity, diabetes mellitus, or hypertension, all of which can increase ROS/RNS levels (Paulus and Tschöpe 2013). Oxidative stress would reduce NO bioavailability, block sGC activity, down-regulate cGMPPKG signalling, and thus cause hypo-phosphorylation of titin at the N2-Bus and pathologically increased passive tension. A (diastolic) heart failure patient may well benefit from the use of NO donors, inhibitors of cGMP-degrading enzymes, antioxidants, or other drugs that block the oxidative-stress effects on titin stiffness (Gladden et al. 2014), in that cardiomyocyte stiffness will be reduced and myocardial diastolic function improved.

Finally, a yet speculative opportunity to help improve symptoms in some cardiac (and skeletal myopathy?) patients may involve promoting the oxidative/nitrosative modification of cysteines in unfolded titin Ig-domains. For instance, when treating patients or dogs in acute heart failure with HNO donors (e.g., Angeli's salt), improvements in both systolic and diastolic mechanical properties (including diastolic stiffness) were observed (Sabbah et al. 2013; Arcaro et al. 2014). The de-stiffening effect in 
diastole could be due in part to a reduced titin stiffness resulting from nitrosative modification ( $S$-nitrosylation) of cysteines in I-band titin Ig-domains, similar to the effect of $S$-glutathionylation on these domains (Alegre-Cebollada et al. 2014). Notably, the HNO donors are considered to exert their effects independent from cGMP-PKG (and cAMP-PKA) signalling.

In conclusion, recent evidence suggests that oxidative/ nitrosative stress-related modifications of titin occur in both cardiac and skeletal myocytes. These modifications can alter titin-based passive stiffness and perhaps modulate additional functions of titin. To which degree the oxidative modifications of the titin springs may be relevant for myocyte stiffness in striated muscle disease, remains to be seen. However, oxidative changes in titin have the potential to serve as biomarkers and become useful drug targets in specific forms of muscle/heart disease.

Acknowledgments We acknowledge financial support by the German Research Foundation (SFB 1002, TP B03) and the European Union (FP7 programme, MEDIA).

Open Access This article is distributed under the terms of the Creative Commons Attribution License which permits any use, distribution, and reproduction in any medium, provided the original author(s) and the source are credited.

\section{References}

Alegre-Cebollada J, Kosuri P, Giganti D, Eckels E, Rivas-Pardo JA, Hamdani N, Warren CM, Solaro RJ, Linke WA, Fernández JM (2014) $S$-glutathionylation of cryptic cysteines enhances titin elasticity by blocking protein folding. Cell 156:1235-1246

Ali MA, Cho WJ, Hudson B, Kassiri Z, Granzier H, Schulz R (2010) Titin is a target of matrix metalloproteinase-2: implications in myocardial ischemia/reperfusion injury. Circulation 122:2039-2047

Allen DG, Lamb GD, Westerblad H (2008) Skeletal muscle fatigue: cellular mechanisms. Physiol Rev 88:287-332

Andrade FH, Reid MB, Westerblad H (2001) Contractile response of skeletal muscle to low peroxide concentrations: myofibrillar calcium sensitivity as a likely target for redox-modulation. FASEB J 15:309-311

Arcaro A, Lembo G, Tocchetti CG (2014) Nitroxyl (HNO) for treatment of acute heart failure. Curr Heart Fail Rep 11:227-235

Avner BS, Shioura KM, Scruggs SB, Grachoff M, Geenen DL, Helseth DL Jr, Farjah M, Goldspink PH, Solaro RJ (2012) Myocardial infarction in mice alters sarcomeric function via post-translational protein modification. Mol Cell Biochem 363:203-215

Baldus S, Müllerleile K, Chumley P et al (2006) Inhibition of xanthine oxidase improves myocardial contractility in patients with ischemic cardiomyopathy. Free Radic Biol Med 41:1282-1288

Balogh A, Santer D, Pásztor ET et al (2014) Myofilament protein carbonylation contributes to the contractile dysfunction in the infarcted LV region of mouse hearts. Cardiovasc Res 101:108-119

Bang ML, Centner T, Fornoff F et al (2001) The complete gene sequence of titin, expression of an unusual approximately
700-kDa titin isoform, and its interaction with obscurin identify a novel Z-line to I-band linking system. Circ Res 89:1065-1072

Barta J, Tóth A, Edes I, Vaszily M, Papp JG, Varró A, Papp Z (2005) Calpain-1-sensitive myofibrillar proteins of the human myocardium. Mol Cell Biochem 278:1-8

Bishu K, Hamdani N, Mohammed SF et al (2011) Sildenafil and B-type natriuretic peptide acutely phosphorylate titin and improve diastolic distensibility in vivo. Circulation 124:2882-2891

Borbély A, Falcao-Pires I, van Heerebeek L, Hamdani N, Edes I, Gavina C, Leite-Moreira AF, Bronzwaer JG, Papp Z, van der Velden J, Stienen GJ, Paulus WJ (2009) Hypophosphorylation of the stiff N2B titin isoform raises cardiomyocyte resting tension in failing human myocardium. Circ Res 104:780-786

Brennan JP, Miller JI, Fuller W, Wait R, Begum S, Dunn MJ, Eaton P (2006) The utility of $N, N$-biotinyl glutathione disulfide in the study of protein $S$-glutathiolation. Mol Cell Proteomics 5:215-225

Bullard B, Ferguson C, Minajeva A et al (2004) Association of the chaperone $\alpha \mathrm{B}$-crystallin with titin in heart muscle. J Biol Chem 279:7917-7924

Canton M, Neverova I, Menabò R, Van Eyk J, Di Lisa F (2004) Evidence of myofibrillar protein oxidation induced by postischemic reperfusion in isolated rat hearts. Am J Physiol Heart Circ Physiol 286:870-877

Canton M, Skyschally A, Menabò R, Boengler K, Gres P, Schulz R, Haude M, Erbel R, Di Lisa F, Heusch G (2006) Oxidative modification of tropomyosin and myocardial dysfunction following coronary microembolization. Eur Heart J 27:875-881

Canton M, Menazza S, Sheeran FL, de Laureto PP, Di Lisa F, Pepe S (2011) Oxidation of myofibrillar proteins in human heart failure. J Am Coll Cardiol 57:300-309

Canton M, Menazza S, Di Lisa F (2014) Oxidative stress in muscular dystrophy: from generic evidence to specific sources and targets. J Muscle Res Cell Motil 35:23-36

Chen FC, Ogut O (2006) Decline of contractility during ischemiareperfusion injury: actin glutathionylation and its effect on allosteric interaction with tropomyosin. Am J Physiol Cell Physiol 290:719-727

Coulis G, Becila S, Herrera-Mendez CH, Sentandreu MA, Raynaud F, Richard I, Benyamin Y, Ouali A (2008) Calpain 1 binding capacities of the N1-line region of titin are significantly enhanced by physiological concentrations of calcium. Biochemistry 47:9174-9183

Dalle-Donne I, Rossi R, Giustarini D, Gagliano N, Lusini L, Milzani A, Di Simplicio P, Colombo R (2001) Actin carbonylation: from a simple marker of protein oxidation to relevant signs of severe functional impairment. Free Radic Biol Med 31:1075-1083

Dalle-Donne I, Giustarini D, Rossi R, Colombo R, Milzani A (2003) Reversible $S$-glutathionylation of $\mathrm{Cys}^{374}$ regulates actin filament formation by inducing structural changes in the actin molecule. Free Radic Biol Med 34:23-32

De Pascali F, Hemann C, Samons K, Chen CA, Zweier JL (2014) Hypoxia and reoxygenation induce endothelial nitric oxide synthase uncoupling in endothelial cells through tetrahydrobiopterin depletion and $S$-glutathionylation. Biochemistry 53:3679-3688

Di Lisa F, Kaludercic N, Carpi A, Menabò R, Giorgio M (2009) Mitochondrial pathways for ROS formation and myocardial injury: the relevance of p66(Shc) and monoamine oxidase. Basic Res Cardiol 104:131-139

Dihman M, Nakayasu ES, Madaiah YH, Reynolds BK, Wen JJ, Almeida IC, Garg NJ (2008) Enhanced nitrosative stress during Trypanosoma cruzi infection causes nitrotyrosine modification of host proteins: implications in Chagas' disease. Am J Pathol 173:728-740 
Dihman M, Zago MP, Nunez S, Amoroso A, Rementeria H, Dousset P, Nunez Burgos F, Garg NJ (2012) Cardiac-oxidized antigens are targets of immune recognition by antibodies and potential molecular determinants in Chagas disease pathogenesis. PLoS One 7:e28449

Disatnik MH, Dhawan J, Yu Y, Beal MF, Whirl MM, Franco AA, Rando TA (1998) Evidence of oxidative stress in mdx mouse muscle: studies of the pre-necrotic state. J Neurol Sci 161:77-84

Doroszko A, Polewicz D, Cadete VJ, Sawicka J, Jones M, SzczesnaCordary D, Cheung PY, Sawicki G (2010) Neonatal asphyxia induces the nitration of cardiac myosin light chain 2 that is associated with cardiac systolic dysfunction. Shock 34:592-600

Eaton P, Byers HL, Leeds N, Ward MA, Shattock MJ (2002) Detection, quantitation, purification, and identification of cardiac proteins $S$-thiolated during ischemia and reperfusion. J Biol Chem 277:9806-9811

El-Shafey AF, Armstrong AE, Terrill JR, Grounds MD, Arthur PG (2011) Screening for increased protein thiol oxidation in oxidatively stressed muscle tissue. Free Radic Res 45:991-999

Fukuda N, Granzier HL (2005) Titin/connectin-based modulation of the Frank-Starling mechanism of the heart. J Muscle Res Cell Motil 26:319-323

Gao WD, Murray CI, Tian Y et al (2012) Nitroxyl-mediated disulfide bond formation between cardiac myofilament cysteines enhances contractile function. Circ Res 111:1002-1011

Gladden JD, Linke WA, Redfield MM (2014) Heart failure with preserved ejection fraction. Pflüg Arch 466:1037-1053

Grützner A, Garcia-Manyes S, Kötter S, Badilla CL, Fernandez JL, Linke WA (2009) Modulation of titin-based stiffness by disulfide bonding in the cardiac titin N2B-unique sequence. Biophys $\mathrm{J}$ 97:825-834

Hamdani N, Bishu KG, Frieling-Salewsky M, Redfield MM, Linke WA (2013a) Deranged myofilament phosphorylation and function in experimental heart failure with preserved ejection fraction. Cardiovasc Res 97:464-471

Hamdani N, Franssen C, Lourenço A et al (2013b) Myocardial titin hypophosphorylation importantly contributes to heart failure with preserved ejection fraction in a rat metabolic risk model. Circ Heart Fail 6:1239-1249

Hamdani N, Krysiak J, Kreusser MM, Neef S, dos Remedios CG, Maier LS, Krüger M, Backs J, Linke WA (2013c) Crucial role for $\mathrm{Ca}^{2+} /$ calmodulin-dependent protein kinase-II in regulating diastolic stress of normal and failing hearts via titin phosphorylation. Circ Res 112:664-674

Hathout Y, Marathi RL, Rayavarapu S et al (2014) Discovery of serum protein biomarkers in the mdx mouse model and crossspecies comparison to Duchenne muscular dystrophy patients. Hum Mol Genet. doi:10.1093/hmg/ddu366 [15 July 2014; Epub ahead of print]

Haycock JW, MacNeil S, Jones P, Harris JB, Mamtle D (1996) Oxidative damage to muscle protein in Duchenne muscular dystrophy. NeuroReport 8:357-361

Haywood GA, Tsao PS, von der Leyen HE et al (1996) Expression of inducible nitric oxide synthase in human heart failure. Circulation 93:1087-1094

Hein S, Scholz D, Fujitani N, Rennollet H, Brand T, Friedl A, Schaper J (1994) Altered expression of titin and contractile proteins in failing human myocardium. J Mol Cell Cardiol 26:1291-1306

Hertelendi Z, Tóth A, Borbély A, Galajda Z, van der Velden J, Stienen GJ, Edes I, Papp Z (2008) Oxidation of myofilament protein sulfhydryl groups reduces the contractile force and its $\mathrm{Ca}^{2+}$ sensitivity in human cardiomyocytes. Antioxid Redox Signal 10:1175-1184

Heusch P, Canton M, Aker S et al (2010) The contribution of reactive oxygen species and p38 mitogen-activated protein kinase to myofilament oxidation and progression of heart failure in rabbits. Br J Pharmacol 160:1408-1416

Heymes C, Bendall JK, Ratajczak P, Cave AC, Samuel JL, Hasenfuss G, Shah AM (2003) Increased myocardial NADPH oxidase activity in human heart failure. J Am Coll Cardiol 41:2164-2171

Hidalgo CG, Hudson B, Bogomolovas J, Zhu Y, Anderson B, Greaser M, Labeit S, Granzier H (2009) PKC phosphorylation of titin's PEVK element: a novel and conserved pathway for modulating myocardial stiffness. Circ Res 105:631-638

Hong SJ, Gokulrangan G, Schöneich C (2007) Proteomic analysis of age dependent nitration of rat cardiac proteins by solution isoelectric focusing coupled to nanoHPLC tandem mass spectrometry. Exp Gerontol 42:639-651

Horowits R, Kempner ES, Bisher ME, Podolsky RJ (1986) A physiological role for titin and nebulin in skeletal muscle. Nature 323:160-164

Inserte J, Hernando V, Garcia-Dorado D (2012) Contribution of calpains to myocardial ischaemia/reperfusion injury. Cardiovasc Res 96:23-31

Kandasamy AD, Chow AK, Ali MA, Schulz R (2010) Matrix metalloproteinase-2 and myocardial oxidative stress injury: beyond the matrix. Cardiovasc Res 85:413-423

Kanski J, Behring A, Pelling J, Schöneich C (2005a) Proteomic identification of 3-nitrotyrosine-containing rat cardiac proteins: effects of biological aging. Am J Physiol Heart Circ Physiol 288:371-381

Kanski J, Hong SJ, Schöneich C (2005b) Proteomic analysis of protein nitration in aging skeletal muscle and identification of nitrotyrosine-containing sequences in vivo by nanoelectrospray ionization tandem mass spectrometry. J Biol Chem 280:24261-24266

Kim JH, Kwak HB, Thompson LV, Lawler JM (2013) Contribution of oxidative stress to pathology in diaphragm and limb muscles with Duchenne muscular dystrophy. J Muscle Res Cell Motil 34:1-13

Kötter S, Gout L, Von Frieling-Salewsky M, Müller AE, Helling S, Marcus K, Dos Remedios C, Linke WA, Krüger M (2013) Differential changes in titin domain phosphorylation increase myofilament stiffness in failing human hearts. Cardiovasc Res 99:648-656

Kötter S, Unger A, Hamdani N, Lang P, Vorgerd M, Nagel-Steger L, Linke WA (2014) Human myocytes are protected from titin aggregation-induced stiffening by small heat shock proteins. J Cell Biol 204:187-202

Krüger M, Linke WA (2006) Protein kinase-A phosphorylates titin in human heart muscle and reduces myofibrillar passive tension. J Muscle Res Cell Motil 27:435-444

Krüger M, Linke WA (2011) The giant protein titin: a regulatory node that integrates myocyte signaling pathways. J Biol Chem 286:9905-9912

Krüger M, Kötter S, Grützner A, Lang P, Andresen C, Redfield MM, Butt E, dos Remedios CG, Linke WA (2009) Protein kinase G modulates human myocardial passive stiffness by phosphorylation of the titin springs. Circ Res 104:87-94

Lahmers S, Wu Y, Call DR, Labeit S, Granzier H (2004) Developmental control of titin isoform expression and passive stiffness in fetal and neonatal myocardium. Circ Res 94:505-513

Lamb GD, Westerblad H (2011) Acute effects of reactive oxygen and nitrogen species on the contractile function of skeletal muscle. J Physiol 589:2119-2127

Lange S, Auerbach D, McLoughlin P, Perriard E, Schäfer BW, Perriard JC, Ehler E (2002) Subcellular targeting of metabolic enzymes to titin in heart muscle may be mediated by DRAL/ FHL-2. J Cell Sci 115:4925-4936

Larkins NT, Murphy RM, Lamb GD (2012) Influences of temperature, oxidative stress, and phosphorylation on binding of heat 
shock proteins in skeletal muscle fibers. Am J Physiol Cell Physiol 303:C654-C665

Li H, Linke WA, Oberhauser AF, Carrion-Vazquez M, Kerkvliet JG, Lu H, Marszalek PE, Fernandez JM (2002) Reverse engineering of the giant muscle protein titin. Nature 418:998-1002

Lim CC, Zuppinger C, Guo X, Kuster GM, Helmes M, Eppenberger HM, Suter TM, Liao R, Sawyer DB (2004) Anthracyclines induce calpain-dependent titin proteolysis and necrosis in cardiomyocytes. J Biol Chem 279:8290-8299

Linke WA (2000) Stretching molecular springs: elasticity of titin filaments in vertebrate striated muscle. Histol Histopathol 15:799-811

Linke WA (2010) Molecular giant vulnerable to oxidative damage: titin joins the club of proteins degraded by matrix metalloproteinase-2. Circulation 122:2002-2004

Linke WA, Fernandez JM (2002) Cardiac titin: molecular basis of elasticity and cellular contribution to elastic and viscous stiffness components in myocardium. J Muscle Res Cell Motil 23:483-497

Linke WA, Hamdani N (2014) Gigantic business: titin properties and function through thick and thin. Circ Res 114:1052-1068

Linke WA, Rudy DE, Centner T, Gautel M, Witt C, Labeit S, Gregorio CC (1999) I-band titin in cardiac muscle is a threeelement molecular spring and is critical for maintaining thin filament structure. J Cell Biol 146:631-644

Lovelock JD, Monasky MM, Jeong EM, Lardin HA, Liu H, Patel BG et al (2012) Ranolazine improves cardiac diastolic dysfunction through modulation of myofilament calcium sensitivity. Circ Res 110:841-850

Makarenko I, Opitz CA, Leake MC, Neagoe C, Kulke M, Gwathmey JK, del Monte F, Hajjar RJ, Linke WA (2004) Passive stiffness changes caused by upregulation of compliant titin isoforms in human dilated cardiomyopathy hearts. Circ Res 95:708-716

Mateja RD, Greaser ML, de Tombe PP (2013) Impact of titin isoform on length dependent activation and cross-bridge cycling kinetics in rat skeletal muscle. Biochim Biophys Acta 1833:804-811

Mathewson MA, Chambers HG, Girard PJ, Tenenhaus M, Schwartz AK, Lieber RL (2014) Stiff muscle fibers in calf muscles of patients with cerebral palsy lead to high passive muscle stiffness. J Orthop Res 32:1667-1674

Mayans O, Wuerges J, Canela S, Gautel M, Wilmanns M (2001) Structural evidence for a possible role of reversible disulphide bridge formation in the elasticity of the muscle protein titin. Structure 9:331-340

Menazza S, Blaauw B, Tiepolo T, Toniolo L, Braghetta P, Spolaore B, Reggiani C, Di Lisa F, Bonaldo P, Canton M (2010) Oxidative stress by monoamine oxidases is causally involved in myofiber damage in muscular dystrophy. Hum Mol Genet 19:4207-4215

Mihm MJ, Yu F, Reiser PJ, Bauer JA (2003) Effects of peroxynitrite on isolated cardiac trabeculae: selective impact on myofibrillar energetic controllers. Biochemistry 85:587-596

Miranda KM (2005) The chemistry of nitroxyl (HNO) and implications in biology. Coord Chem Rev 249:433-455

Mollica JP, Dutka TL, Merry TL, Lamboley CR, McConell GK, McKenna MJ, Murphy RM, Lamb GD (2012) S-glutathionylation of troponin I (fast) increases contractile apparatus $\mathrm{Ca}^{2+}$ sensitivity in fast-twitch muscle fibres of rats and humans. J Physiol 590:1443-1463

Morano I, Hädicke K, Grom S, Koch A, Schwinger RH, Böhm M, Bartel S, Erdmann E, Krause EG (1994) Titin, myosin light chains and C-protein in the developing and failing human heart. J Mol Cell Cardiol 26:361-368

Murphy RM, Verburg E, Lamb GD (2006) $\mathrm{Ca}^{2+}$ activation of diffusible and bound pools of mu-calpain in rat skeletal muscle. J Physiol 576:595-612
Mymrikov EV, Seit-Nebi AS, Gusev NB (2011) Large potentials of small heat shock proteins. Physiol Rev 91:1123-1159

Neagoe C, Kulke M, del Monte F, Gwathmey JK, de Tombe PP, Hajjar RJ, Linke WA (2002) Titin isoform switch in ischemic human heart disease. Circulation 106:1333-1341

Olsson MC, Krüger M, Meyer LH, Ahnlund L, Gransberg L, Linke WA, Larsson L (2006) Fibre type-specific increase in passive muscle tension in spinal cord-injured subjects with spasticity. J Physiol 577:339-352

Opitz CA, Leake MC, Makarenko I, Benes V, Linke WA (2004) Developmentally regulated switching of titin size alters myofibrillar stiffness in the perinatal heart. Circ Res 94:967-975

Passarelli C, Di Venere A, Piroddi N et al (2010) Susceptibility of isolated myofibrils to in vitro glutathionylation: potential relevance to muscle functions. Cytoskeleton (Hoboken) 67:81-89

Patel BG, Wilder T, Solaro RJ (2013) Novel control of cardiac myofilament response to calcium by $S$-glutathionylation at specific sites of myosin binding protein C. Front Physiol 4:336

Paulus WJ, Tschöpe C (2013) A novel paradigm for heart failure with preserved ejection fraction: comorbidities drive myocardial dysfunction and remodeling through coronary microvascular endothelial inflammation. J Am Coll Cardiol 62:263-271

Pizarro GO, Ogut O (2009) Impact of actin glutathionylation on the actomyosin-S1 ATPase. Biochemistry 48:7533-7538

Polewicz D, Cadete VJ, Doroszko A, Hunter BE, Sawicka J, Szczesna-Cordary D, Light PE, Sawicki G (2011) Ischemia induced peroxynitrite dependent modifications of cardiomyocyte MLC1 increases its degradation by MMP-2 leading to contractile dysfunction. J Cell Mol Med 15:1136-1147

Rouillon J, Zocevic A, Leger T, Garcia C, Camadro JM, Udd B, Wong B, Servais L, Voit T, Svinartchouk F (2014) Proteomics profiling of urine reveals specific titin fragments as biomarkers of Duchenne muscular dystrophy. Neuromuscul Disord 24:563-573

Sabbah HN, Tocchetti CG, Wang M, Daya S, Gupta RC, Tunin RS, Mazhari R, Takimoto E, Paolocci N, Cowart D, Colucci WS, Kass DA (2013) Nitroxyl (HNO): a novel approach for the acute treatment of heart failure. Circ Heart Fail 6:1250-1258

Sawicki G, Leon H, Sawicka J, Sariahmetoglu M, Schulze CJ, Scott PG, Szczesna-Cordary D, Schulz R (2005) Degradation of myosin light chain in isolated rat hearts subjected to ischemiareperfusion injury: a new intracellular target for matrix metalloproteinase-2. Circulation 112:544-552

Sawyer DB, Siwik DA, Xiao L, Pimentel DR, Singh K, Colucci WS (2002) Role of oxidative stress in myocardial hypertrophy and failure. J Mol Cell Cardiol 34:379-388

Schrammel A, Behrends S, Schmidt K, Koesling D, Mayer B (1996) Characterization of $1 \mathrm{H}-[1,2,4]$ oxadiazolo[4,3-a]quinoxalin-1one as a heme-site inhibitor of nitric oxide-sensitive guanylyl cyclase. Mol Pharmacol 50:1-5

Shah AM, MacCarthy PA (2000) Paracrine and autocrine effects of nitric oxide on myocardial function. Pharmacol Ther 86:49-86

Sheikh F, Raskin A, Chu PH et al (2008) An FHL1-containing complex within the cardiomyocyte sarcomere mediates hypertrophic biomechanical stress responses in mice. J Clin Investig 118:3870-3880

Smith MA, Reid MB (2006) Redox modulation of contractile function in respiratory and limb skeletal muscle. Respir Physiol Neurobiol 151:229-241

Steinberg SF (2013) Oxidative stress and sarcomeric proteins. Circ Res 112:393-405

St-Pierre J, Buckingham JA, Roebuck SJ, Brand MD (2002) Topology of superoxide production from different sites in the mitochondrial electron transport chain. J Biol Chem 277:44784-44790

Sung MM, Schulz CG, Wang W, Sawicki G, Bautista-López NL, Schulz R (2007) Matrix metalloproteinase-2 degrades the 
cytoskeletal protein alpha-actinin in peroxynitrite mediated myocardial injury. J Mol Cell Cardiol 43:429-436

Terrill JR, Radley-Crabb HG, Iwasaki T, Lemckert FA, Arthur PG, Grounds MD (2013) Oxidative stress and pathology in muscular dystrophies: focus on protein thiol oxidation and dysferlinopathies. FEBS J 280:4149-4164

Tiago T, Simão S, Aureliano M, Martín-Romero FJ, GutiérrezMerino C (2006) Inhibition of skeletal muscle S1-myosin ATPase by peroxynitrite. Biochemistry 45:3794-3804

Trombitás K, Freiburg A, Centner T, Labeit S, Granzier H (1999) Molecular dissection of N2B cardiac titin's extensibility. Biophys J 77:3189-3196

van Heerebeek L, Hamdani N, Falcão-Pires I et al (2012) Low myocardial protein kinase $\mathrm{G}$ activity in heart failure with preserved ejection fraction. Circulation 126:830-839

Wang W, Schulze CJ, Suarez-Pinzon WL, Dyck JR, Sawicki G, Schulz R (2002) Intracellular action of matrix metalloproteinase2 accounts for acute myocardial ischemia and reperfusion injury. Circulation 106:1543-1549

Ward DG, Ashton PR, Trayer HR, Trayer IP (2001) Additional PKA phosphorylation sites in human cardiac troponin I. Eur J Biochem 268:179-185
Warren CM, Krzesinski PR, Campbell KS, Moss RL, Greaser ML (2004) Titin isoform changes in rat myocardium during development. Mech Dev 121:1301-1312

Wright VP, Reiser PJ, Clanton TL (2009) Redox modulation of global phosphatase activity and protein phosphorylation in intact skeletal muscle. J Physiol 587:5767-5781

Xia Y, Tsai AL, Berka V, Zweier JL (1998) Superoxide generation from endothelial nitric-oxide synthase. $\mathrm{A} \mathrm{Ca}^{2+} /$ calmodulindependent and tetrahydrobiopterin regulatory process. J Biol Chem 273:25804-25808

Yamasaki R, Wu Y, McNabb M, Greaser M, Labeit S, Granzier H (2002) Protein kinase A phosphorylates titin's cardiac-specific N2B domain and reduces passive tension in rat cardiac myocytes. Circ Res 90:1181-1188

Zhang YH, Jin CZ, Jang JH, Wang Y (2014) Molecular mechanisms of neuronal nitric oxide synthase in cardiac function and pathophysiology. J Physiol 592:3189-3200 